\title{
Immunological indicators of coeliac disease activity are not altered by long-term oats challenge
}

\author{
S. E. J. Cooper, ${ }^{\star}$ N. P. Kennedy, \\ B. M. Mohamed, ${ }^{\ddagger}$ M. Abuzakouk, ${ }^{9}$ \\ J. Dunne, ${ }^{\star}$ G. Byrne, ${ }^{\star}$ G. McDonald, ${ }^{\dagger}$ \\ A. Davies, ${ }^{\ddagger}$ C. Edwards, ${ }^{\ddagger}$ J. Kelly ${ }^{\S}$ and \\ C. F. Feighery* \\ Departments of ${ }^{\star}$ Immunology and \\ ${ }^{\dagger}$ Histopathology, St James's Hospital and Trinity \\ College Dublin, ${ }^{*}$ Department of Clinical Medicine \\ and Institute of Molecular Medicine, Trinity

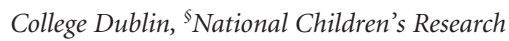 \\ Centre, Our Lady's Children's Hospital, Crumlin, \\ Dublin, Ireland, and 'Department of \\ Immunology, Hull Royal Infirmary, Hull, UK
}

Accepted for publication 11 October 2012

Correspondence: C. F. Feighery, Department of

Immunology, St. James's Hospital, Trinity

College, Dublin 8, Ireland.

E-mail: con.feighery@tcd.ie

\begin{abstract}
Summary
Coeliac disease is a gluten-sensitive enteropathy that develops in genetically susceptible individuals. The disease exhibits many features of an autoimmune disorder. These include the production of highly specific antiendomysial autoantibodies directed against the enzyme tissue transglutaminase. It is well accepted that wheat-, barley- and rye-based foods should be excluded in the gluten-free diet. Although several studies report that oats ingestion is safe in this diet, the potential toxicity of oats remains controversial. In the current study, 46 coeliac patients ingested oats for 1 year and were investigated for a potential immunogenic or toxic effect. Stringent clinical monitoring of these patients was performed and none experienced adverse effects, despite ingestion of a mean of $286 \mathrm{~g}$ of oats each week. Routine histological analysis of intestinal biopsies showed improvement or no change in $95 \%$ of the samples examined. Furthermore, tissue transglutaminase expression in biopsy samples, determined quantitatively using the IN Cell Analyzer, was unchanged. Employing immunohistochemistry, oats ingestion was not associated with changes in intraepithelial lymphocyte numbers or with enterocyte proliferation as assessed by Ki-67 staining. Finally, despite the potential for tissue transglutaminase to interact with oats, neither endomysial nor tissue transglutaminase antibodies were generated in any of the patients throughout the study. To conclude, this study reaffirms the lack of oats immunogenicity and toxicity to coeliac patients. It also suggests that the antigenic stimulus caused by wheat exposure differs fundamentally from that caused by oats.
\end{abstract}

Keywords: coeliac disease, immunological parameters, oats challenge, tissue transglutaminase

\section{Introduction}

Coeliac disease is a gluten-sensitive enteropathy that develops in genetically susceptible individuals [1-3]. The presence of gluten in the diet is essential for coeliac disease to manifest, and a gluten-free diet is a highly effective treatment for this disorder. The traditional diet is based on the exclusion of all wheat protein products and, until recently, barley, rye and oats cereal foods were also excluded. However, unequivocal evidence that these latter three cereals are toxic is sparse. Because oats are related phylogenetically more distantly to the other cereals [4], their true toxicity was particularly questioned. This led to the original oats challenge studies, which reported that oats did not cause activation of coeliac disease [5,6]. More recent studies of paediatric and adult coeliac patients supported these earlier observations [7-11]. However, other investigators reported that oats could activate coeliac disease in some patients, and suggested that if oats were taken in sufficient quantity over a longer time-period the cereal might prove to be toxic $[12,13]$. Moreover, it was postulated that the mucosal inflammation in oats-reactive patients was caused by oats-avenin activated intestinal $\mathrm{T}$ cells [13]. It was demonstrated that the oats reactivity of cell lines was human leucocyte antigen (HLA)-DQ2-restricted and enhanced by deamidation of peptides by tissue transglutaminase. As a consequence of these reports, and continuing concerns about the safety of oats, in two recent reviews caution was 


\section{S. E. J. Cooper et al.}

advised and it was suggested that oats might not be tolerated by all coeliac patients $[14,15]$.

In view of the continuing debate about oats toxicity, a group of treated coeliac patients taking $50 \mathrm{~g}$ of oats daily for 1 year were investigated in this study. Clinical monitoring of patients was particularly stringent and included maintaining a daily symptom diary with formal clinical evaluation every 3 months. Particular focus was given to immunological events, and these included monitoring the expression of tissue transglutaminase protein in intestinal biopsy tissue; documenting the extent of epithelial infiltration by lymphocytes and enterocyte proliferation in intestinal biopsies; and monitoring levels of endomysial and anti-tissue transglutaminase autoantibodies.

\section{Materials and methods}

\section{Patients}

Fifty-four patients with biopsy proven coeliac disease were recruited into the study. The oats were sourced from Peter Kölln and confirmed to be free from other grains [6]. A target oats intake of $50 \mathrm{~g}$ per day for 1 year was planned. Eight patients failed to complete the study, and details of the remaining 46 are given in Table 1. Thirty-seven of these patients were categorized as having treated coeliac disease, adhering to a gluten-free diet for a mean of 10 years. A further nine patients were diagnosed more recently, and six of these started oats within 3 months of their diagnosis and commencing a gluten-free diet.

Approval for the study was granted by the Hospital Ethics Committee.

\section{Clinical monitoring}

Patients were requested to maintain a symptom diary for the duration of the study and were assessed clinically on a 3-monthly basis. Patients were questioned about general wellbeing and specifically about the development of symptoms such as mouth ulcers, dyspepsia, alteration in bowel habit and skin rash or itch. They were also weighed and their body mass index calculated. Blood tests, including endomysial antibody serology, haemoglobin level, white cell differential and platelet count, were performed on six occasions throughout the study.

\section{Coeliac antibody tests}

The endomysial antibody assay was carried out using an indirect immunofluorescence technique, as described previously [16]. A commercial enzyme-linked immunosorbent assay (ELISA) kit (Celikey; Pharmacia Diagnostics, Uppsala, Sweden) was used to measure immunoglobulin (Ig)A antitissue transglutaminase antibodies, and this test was performed on serum samples obtained at study completion.

\section{Small intestinal histology}

All patients had a duodenal biopsy taken prior to the start of the oats challenge. In the majority (78\%), the biopsy was taken within a 12-month period prior to commencement of the oats challenge. In eight patients, with indicators that their disease was in stable remission, a biopsy taken more than 1 year before the challenge was used as the baseline test. A second biopsy was taken at the end of the study, and in $87 \%$ this was taken within 8 weeks of study completion. The haematoxylin and eosin-stained duodenal biopsy sections were examined by an experienced histopathologist in a blinded and random manner. Features suggestive of coeliac disease activity, including villous atrophy, increased intraepithelial lymphocytes, enterocyte nuclear disarray, crypt hyperplasia and increased lamina propria cellular infiltrate, were documented. A Marsh score [17] was assigned in the following manner: Marsh 0, normal duodenal architecture; Marsh 1, normal duodenal architecture with an increase in intraepithelial lymphocytes; Marsh 2, partial villous atrophy; and Marsh 3, total villous atrophy.

\section{Immunohistochemistry and immunofluorescence}

Immunohistochemical staining was carried out on $4-\mu \mathrm{m}-$ thick formalin-fixed paraffin-embedded tissue sections from 19 patients, as described previously [18]. Following antigen retrieval with citrate buffer, slides were incubated with anti-Ki-67, anti-CD3 or anti-CD8 antibodies (all from Novocastra Laboratories, Newcastle upon Tyne, UK), followed by the avidin-biotin-peroxidase complex detection procedure (Vector Laboratories, Burlingame, CA, USA). Sections were then incubated with diaminobenzidine and counterstained with haemotoxylin (Sigma-Aldrich, Arklow,

Table 1. Details of 46 biopsy-proven coeliac patients.

\begin{tabular}{lll}
\hline & \multicolumn{1}{c}{ Treated patients } & Recently diagnosed patients \\
\hline Number & 37 & \\
Sex & 14 male, 23 female & 2 male, 7 female \\
Age (years) & Mean $46 \cdot 7($ range $18 \cdot 7-76 \cdot 8)$ & Mean $51 \cdot 2($ range $28 \cdot 3-65 \cdot 1)$ \\
Duration of GFD (years) & Mean $9 \cdot 7($ range $1-40 \cdot 1)$ & Mean $0 \cdot 4($ range $0 \cdot 1-0 \cdot 9)$ \\
EMA at commencement & 34 neg, 1 wpos, 2 pos & neg wpos, 4 pos \\
Histology (Marsh grade) & $30(0,1), 7(2,3)$ & $2(1), 7(2,3)$
\end{tabular}

EMA: endomysial antibody; GFD: gluten-free diet; neg: negative; wpos: weak positive; pos: positive. 
Wicklow, Ireland). Finally, the slides were coded and assessed in a blinded manner. In the case of anti-Ki-67stained sections, the number of positively stained cells within five fields were counted and the percentage of positive cells calculated; for CD3 and CD8 the number of positively stained cells within 500 cells of the surface epithelial layer were counted and the percentage calculated.

In further immunofluorescence studies, tissue sections were incubated with antibody to tissue transglutaminase (Roboscreen, Leipzig, Germany) followed by an AlexaFluor ${ }^{568}$-conjugated secondary goat anti-rabbit antibody (BioSciences, Dublin, Ireland). Sections were also incubated with antibody to smooth muscle alpha-actin (Sigma-Aldrich) followed by a secondary goat anti-mouse fluorescein isothiocyanate (FITC) antibody (Dako, Glostrup, Denmark). In order to visualize nuclei, slides were then incubated with Hoechst 33258 (Sigma-Aldrich). The extent of antibody labelling in peri-cryptal regions of biopsy pairs was then determined by high-resolution digital fluorescent microscopy followed by advanced image analysis [19] using the IN Cell Analyzer 1000 HCA platform (GE Healthcare, Little Chalfont, UK). Data were expressed as the percentage total area of tissue staining positive for smooth muscle alpha-actin and tissue transglutaminase (with a threshold of $\times 1.5$ above background).

\section{Results}

\section{Patient clinical assessments}

Forty-six of the 54 patients who enrolled initially completed the study. The reasons for withdrawal in the eight patients were failure to adhere to the study protocol (five patients); emigration (two patients); and the development of breast cancer (one patient). None of these eight patients reported adverse reactions to the oats supplement.

The 46 patients who completed the study consumed a mean of $286 \mathrm{~g}$ oats per week (range $97-513 \mathrm{~g}$ ) for a median duration of 48 weeks (range 33-58). Several patients reported mild symptoms such as flatus and abdominal distension with oats addition to their diet. No significant change was seen in body weights or body mass indices. Similarly, routine laboratory tests remained normal for the duration of the oats challenge.

\section{Small intestinal histology}

Following oats challenge, suitable biopsy material was available for routine histological analysis on 44 of the 46 patients (Table 2). In 42 patients $(95 \cdot 5 \%)$ the histological lesion had either improved or not changed. Two patients showed histological disimprovement while ingesting oats (Table 2). In one of these, the level of disimprovement was marginal (from Marsh grade 1 to Marsh 2); moreover, both dietetic and serological review suggested that the patient was not
Table 2. Summary of serology and histology findings after oats challenge.

\begin{tabular}{llc}
\hline & Treated patients $(n=37)$ & $\begin{array}{c}\text { Recently diagnosed } \\
\text { patients }(n=9)\end{array}$ \\
\hline EMA & 37 neg & 7 neg; 1 pos, 1 w.pos \\
tTG antibody & 37 neg & 7 neg; 2 pos $(5 \cdot 1$ and \\
& & $16 \cdot 6 \mathrm{AU})^{\dagger}$ \\
Histology & 33 - improved or no change & $\begin{array}{c}6 \text { improved; } 3 \text { no } \\
\text { change }\end{array}$ \\
& $2-$ disimproved $^{*}$ 2 nd. & chand \\
\hline
\end{tabular}

${ }^{*}$ Neither patient was fully dietary compliant. ${ }^{\dagger}$ In one of these patients, histology had improved; in the second, the Marsh 3 lesion was unchanged. EMA: endomysial antibody; n.d.: not done, biopsy unsuitable; neg: negative; pos: positive; tTG: tissue transglutaminase; w.pos: weak positive.

fully compliant with the gluten-free diet. The second patient also had a Marsh grade 2 lesion at study completion but then continued to ingest oats for a further 8 months, and a third biopsy taken at this time showed marked histological improvement, with a Marsh grade 1 lesion.

\section{Coeliac antibody serology}

At the commencement of the study, 37 patients had a negative endomysial antibody test (Table 1). Repeat testing throughout the study confirmed that almost all patients remained antibody-negative, with $89 \%$ of the total 275 tests in the study giving negative results. Only 16 samples were endomysial antibody-positive and these were sourced from four newly diagnosed coeliac patients and from two treated patients with known poor dietary compliance. At the completion of oats challenge, 44 of the 46 patients had a negative endomysial antibody test. The two patients with positive endomysial antibodies at study end were among the recently diagnosed subgroup (Table 2). Tissue transglutaminase autoantibody tests mirrored endomysial antibody results, and 44 subjects had a negative test $(<5$ arbitrary units, AU). The two patients who were endomysial antibody-positive had tissue transglutaminase autoantibody levels that were minimally elevated $(5 \cdot 1 \mathrm{AU})$ or moderately elevated $(16 \cdot 8 \mathrm{AU})$.

\section{Immunohistochemistry}

Pre- and post-oats biopsy samples in 19 patients were stained for expression of Ki67, CD3 and CD8. The addition of daily oats caused no significant change in the extent of staining for any of these markers (Table 3 ). In the case of Ki67, 53\% of enterocytes stained positively before oats and $56 \%$ at study end [ $95 \%$ CI $-11 \cdot 57$ to $5 \cdot 47 \%$ ]. The percentage of cells staining with anti-CD3 was $24 \%$ before and $23 \%$ after oats challenge [ $95 \% \mathrm{CI}-4 \cdot 25$ to $5 \cdot 89$ ]. Similarly, with anti-CD8 antibody, the percentage of cells with positive staining before oats was $31 \%$ and $28 \%$ following oats ingestion [95\% CI $-4 \cdot 49$ to $10 \cdot 01$ ]. 


\section{S. E. J. Cooper et al.}

Table 3. Immunohistochemistry and immunofluorescence results.

\begin{tabular}{lccl}
\hline & $\begin{array}{c}\text { Pre-oats } \\
(n=19)\end{array}$ & $\begin{array}{c}\text { Post-oats } \\
(n=19)\end{array}$ & \\
\hline Ki-67\% $(n=19)$ & $53 \pm 15 \%$ & $56 \pm 18 \%$ & $P=0 \cdot 47$ \\
CD3\% $(n=19)$ & $24 \pm 7 \%$ & $23 \pm 9 \%$ & $P=0 \cdot 74$ \\
CD8\% $(n=19)$ & $31 \pm 11 \%$ & $28 \pm 15 \%$ & $P=0 \cdot 43$ \\
tTG\% $(n=16)$ & $1 \cdot 02 \pm 0 \cdot 88 \%$ & $1 \cdot 24 \pm 0 \cdot 86 \%$ & $P=0 \cdot 3741$ \\
SM $\alpha$-actin $\%(n=16)$ & $2 \cdot 42 \pm 1 \cdot 55 \%$ & $3 \cdot 23 \pm 2 \cdot 21 \%$ & $P=0 \cdot 1602$
\end{tabular}

The percentage of enterocytes expressing Ki-67 and percentage of intraepithelial cells expressing CD3 and CD8 before and after oats challenge are shown. The percentage of total tissue area expressing tissue transglutaminase (tTG) and smooth muscle alpha actin (SM $\alpha$-actin) before and after oats ingestion is also shown.

\section{Quantitative immunofluorescence}

To examine further the potential immunogenic or toxic effect caused by oats, pre- and post-oats biopsy sections from 16 patients were stained with anti-tissue transglutaminase and anti-smooth muscle alpha-actin antibodies. Elongated stellate cells in the peri-cryptal region, just beneath the basement membrane, were found to express both proteins. These cells were identified as myofibroblasts, based on their morphological appearance and expression of smooth muscle alpha-actin (Fig. 1).

The extent of antibody labelling in peri-cryptal regions was then determined, employing high-resolution digital fluorescent microscopy followed by image analysis using the IN Cell Analyzer [19]. Expression of tissue transglutaminase before oats was $1.02 \%$ and after oats $1 \cdot 24 \%$ [95\% CI -0.75 to $0 \cdot 30$ ], $P=0 \cdot 3741$, not significant (n.s.). Smooth muscle alpha-actin expression was $2 \cdot 42 \%$ before oats and $3.23 \%$ after oats [95\% CI -1.99 to 0.36$] P=0 \cdot 1602$, n.s. (Table 3).

\section{Discussion}

In this study, 46 patients with coeliac disease adhering to a gluten-free diet added oats to their daily diet for 1 year, and none experienced significant adverse effects. Detailed clinical, serological and histological evaluations were performed throughout the study and oats ingestion did not cause activation of coeliac disease. Tissue transglutaminase and smooth muscle alpha actin expression in intestinal histological sections were also measured quantitatively and levels were not altered by daily oats ingestion.

Fig. 1. IN cell analysis: image produced on IN Cell Analyzer 1000 showing nuclear (blue), tissue transglutaminase (red) and smooth muscle alpha-actin (green) staining as well as tissue transglutaminase/smooth muscle alpha-actin co-localization (yellow) (a), images from individual channels showing tissue transglutaminase staining only (b) and smooth muscle alpha-actin staining only (c). The level of tissue transglutaminase and smooth muscle alpha-actin expression was calculated as a percentage of total tissue area.
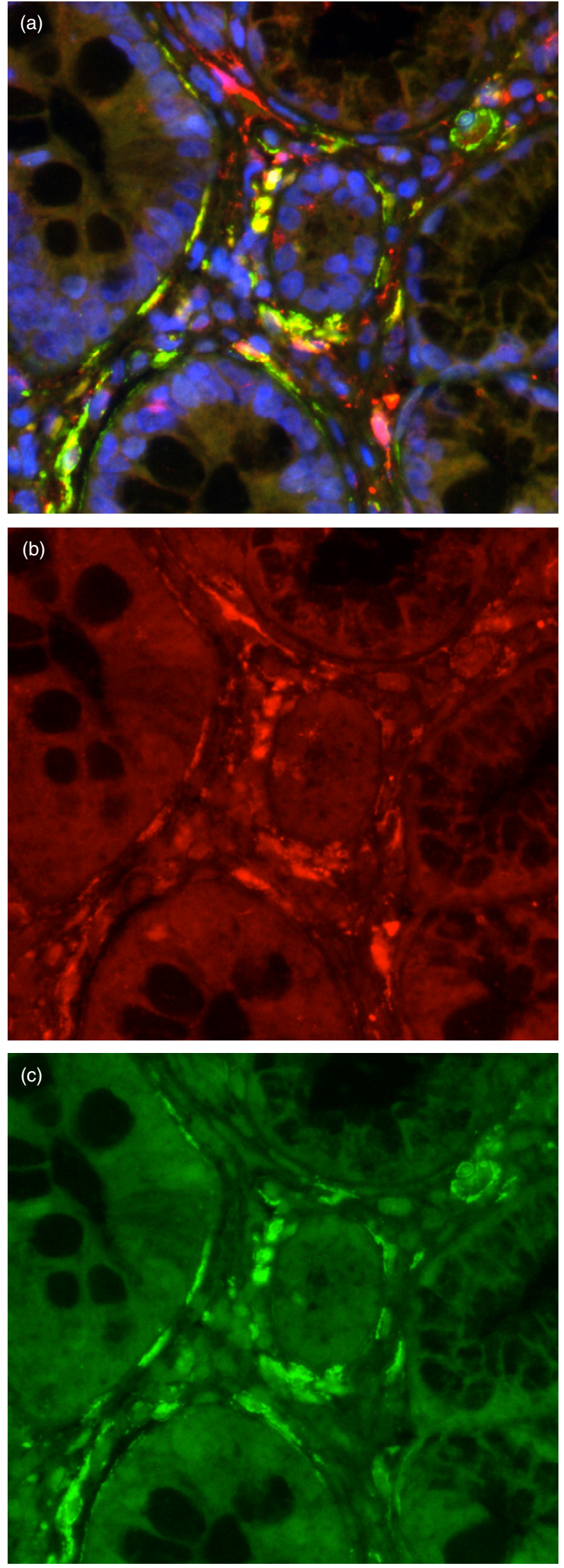
Routine histological analysis of tissue sections after oats challenge showed histological improvement or no change in $95 \%$ of the available samples from 42 of the 44 patients. In the two remaining subjects, the inflammatory lesion had disimproved but, in both, poor adherence to the gluten-free diet was documented and was considered responsible. More detailed analysis was performed on samples from 19 subjects. Whereas infiltration of the epithelium by $\mathrm{CD}^{+} \mathrm{T}$ cells is a classic finding in activation of the coeliac lesion $[11,20]$, in this study oats challenge caused no change in these cell numbers. A similar finding has been made in previous studies $[11,21]$. Similarly, oats in the diet did not alter the extent of enterocyte Ki67 expression, in keeping with the findings of our earlier 3-month challenge study [22]. In patients with active coeliac disease [23-25], and following gliadin challenge in organ culture experiments [23], increased expression of Ki67 by epithelial cells reflecting increased cell turnover has been reported.

The IN Cell Analyzer, which enables the extent and intensity of fluorescence staining to be documented digitally [19], was used to measure the level of expression of tissue transglutaminase and smooth muscle alpha actin proteins in biopsy tissue. Oats ingestion for 1 year caused no change in the level of expression of either molecule. Smooth muscle alpha actin was expressed primarily in elongated stellate cells, identifying these cells as myofibroblasts [26], and these were found in a peri-cryptal location. Tissue transglutaminase was also expressed strongly in these cells. This concurs with earlier reports of expression of this enzyme in cells with a similar morphology [27]. Increased tissue transglutaminase expression in the coeliac small intestine has been reported previously [27-29], and expression has been shown to decrease with gluten-free diet therapy $[28,29]$. Several studies have demonstrated that tissue transglutaminase plays a role in inflammation and wound healing [30-33]; nuclear factor (NF)- $\mathrm{B}$ signalling, which is elevated in the coeliac small intestine [34], may mediate its increased expression. In addition to increased expression of this enzyme, we have also observed increased smooth muscle alpha actin expression in active coeliac biopsies in comparison to biopsies from treated subjects or normal controls (manuscript in preparation).

If oats have the potential to activate coeliac disease and behave like other toxic cereals, as has been reported [13], it might be expected that oats ingestion would result in the generation of an anti-endomysial or anti-tissue transglutaminase antibody response. However, despite a mean oats intake of $286 \mathrm{~g}$ per week, the patients in this study did not develop these antibodies. Other oats challenge studies have reported a similar finding [8-11]. During this study, only four newly diagnosed coeliac patients and two treated patients with known poor dietary compliance were positive for anti-endomysial antibodies. Samples at the end of the study were also tested for anti-tissue transglutaminase antibody levels and the results concurred with the endomysial antibody tests.

The potential immunogenicity and toxicity of oats to patients with coeliac disease continues to be debated [13-15]. Avenin is the alcohol-soluble protein fraction of oats and contains some homologous sequences with the equivalent fractions in wheat (gliadin), barley (hordein) and rye (secalin) [35]. Moreover, some avenin peptide sequences are susceptible to tissue transglutaminase deamidation and found to induce proliferation of gliadin-reactive $\mathrm{T}$ cell lines with production of interferon (IFN) $-\gamma$ [35]. In the study by Arentz-Hansen et al. [13], avenin-reactive T cell lines were generated, with avenin reactivity enhanced by the addition of tissue transglutaminase. Furthermore, the reaction was shown to be HLA-DQ2-restricted. Although the overall properties of avenin, including a lower number of proline residues, make this cereal less immunogenic to coeliac patients, it was argued none the less that in some individuals avenin-reactive $\mathrm{T}$ cells could activate coeliac disease.

There are many lines of evidence against oats being toxic in coeliac patients, including the fact that the avenin content of oats is considerably lower than equivalent proteins in wheat, barley and rye [4]. Many clinical studies have found no evidence of oats toxicity and several of these, including this study, have been of extensive duration, lasting a year or longer $[10,11,21]$. Several of these studies have been on children, and children commonly display rapid evidence of toxicity when given a gluten challenge $[11,20]$. Even when detailed immunohistological examination was performed on biopsy tissue after oats challenge, no evidence of toxicity was observed, as described here and in other studies $[11,22,24]$.

In conclusion, detailed analysis of the large patient cohort reported in this study reaffirms the lack of oats toxicity to coeliac patients. This conclusion is based on the absence of clinical symptoms, serological changes or histological markers of disease activity during oats consumption. The findings also raise fundamental issues concerning differences in the antigenic stimulus caused by gliadin exposure in coeliac disease, compared with avenin exposure.

\section{Acknowledgements}

We would like to thank the patients for their willing participation in the study. Rolled oats were generously supplied by Peter Kölln, Germany, and confirmed to be free of other grains by the laboratory of the late Enrique Mendez $\mathrm{PhD}$ (Spain). Susan Gamble RGN helped in the organization of the study.

\section{Disclosure}

The work was supported in part by a grant from Nutricia Ireland Ltd. 


\section{References}

1 Green PH, Cellier C. Celiac disease. N Engl J Med 2007; 357:173143.

2 Feighery C. Fortnightly review: coeliac disease. BMJ 1999; 319:236-9.

3 United European Gastroenterology. When is a coeliac a coeliac? Report of a working group of the United European Gastroenterology Week in Amsterdam, 2001. Eur J Gastroenterol Hepatol 2001; 13:1123-8.

4 Shewry PR. Cereal proteins and coeliac disease. In: Marsh MN, ed. Coeliac disease. Oxford: Blackwell Scientific, 1992:305-48.

5 Janatuinen EK, Pikkarainen PH, Kemppainen TA et al. A comparison of diets with and without oats in adults with celiac disease. N Engl J Med 1995; 333:1033-7.

6 Srinivasan U, Leonard N, Jones E et al. Absence of oats toxicity in adult coeliac disease. BMJ 1996; 313:1300-1.

7 Hoffenberg EJ, Haas J, Drescher A et al. A trial of oats in children with newly diagnosed celiac disease. J Pediatr 2000; 137:361-6.

8 Hogberg L, Laurin P, Falth-Magnusson K et al. Oats to children with newly diagnosed coeliac disease: a randomised double blind study. Gut 2004; 53:649-54.

9 Peraaho M, Kaukinen K, Mustalahti K et al. Effect of an oatscontaining gluten-free diet on symptoms and quality of life in coeliac disease. A randomized study. Scand J Gastroenterol 2004; 39:27-31.

10 Kemppainen TA, Heikkinen MT, Ristikankare MK et al. Unkilned and large amounts of oats in the coeliac disease diet: a randomized, controlled study. Scand J Gastroenterol 2008; 43:1094101.

11 Holm K, Maki M, Vuolteenaho N et al. Oats in the treatment of childhood coeliac disease: a 2-year controlled trial and a longterm clinical follow-up study. Aliment Pharmacol Ther 2006; 23:1463-72.

12 Lundin KE, Nilsen EM, Scott HG et al. Oats induced villous atrophy in coeliac disease. Gut 2003; 52:1649-52.

13 Arentz-Hansen H, Fleckenstein B, Molberg O et al. The molecular basis for oat intolerance in patients with celiac disease. PLoS Med 2004; 1:e1.

14 Haboubi NY, Taylor S, Jones S. Coeliac disease and oats: a systematic review. Postgrad Med J 2006; 82:672-8.

15 Garsed K, Scott BB. Can oats be taken in a gluten-free diet? A systematic review. Scand J Gastroenterol 2007; 42:171-8.

16 Feighery C, Weir DG, Whelan A et al. Diagnosis of glutensensitive enteropathy: is exclusive reliance on histology appropriate? Eur J Gastroenterol Hepatol 1998; 10:919-25.

17 Marsh MN. Mucosal pathology in gluten sensitivity. In: Marsh MN, ed. Coeliac disease. Oxford: Blackwell Scientific, 1995:13691.

18 Mohamed BM, Feighery C, Kelly J et al. Increased protein expression of matrix metalloproteinases $-1,-3$, and -9 and TIMP-1 in patients with gluten-sensitive enteropathy. Dig Dis Sci 2006; 51:1862-8.
19 Mohamed BM, Feighery C, Williams Y et al. The use of Cellomics to study enterocyte cytoskeletal proteins in coeliac disease patients. Cent Eur J Biol 2008; 3:258-67.

20 Catassi C, Rossini M, Ratsch IM et al. Dose dependent effects of protracted ingestion of small amounts of gliadin in coeliac disease children: a clinical and jejunal morphometric study. Gut 1993; 34:1515-9.

21 Kemppainen T, Janatuinen E, Holm K et al. No observed local immunological response at cell level after five years of oats in adult coeliac disease. Scand J Gastroenterol 2007; 42:54-9.

22 Srinivasan U, Jones E, Carolan J et al. Immunohistochemical analysis of coeliac mucosa following ingestion of oats. Clin Exp Immunol 2006; 144:197-203.

23 Maiuri L, Ciacci C, Raia V et al. FAS engagement drives apoptosis of enterocytes of coeliac patients. Gut 2001; 48:418-24.

24 Settakorn J, Leong AS. Immunohistologic parameters in minimal morphologic change duodenal biopsies from patients with clinically suspected gluten-sensitive enteropathy. Appl Immunohistochem Mol Morphol 2004; 12:198-204.

25 Mohamed BM, Feighery C, Coates C et al. The absence of a mucosal lesion on standard histological examination does not exclude diagnosis of celiac disease. Dig Dis Sci 2008; 53:52-61.

26 Powell DW, Mifflin RC, Valentich JD et al. Myofibroblasts. I. Paracrine cells important in health and disease. Am J Physiol 1999; 277:C1-9.

27 Skovbjerg H, Hansen GH, Niels-Christiansen LL et al. Intestinal tissue transglutaminase in coeliac disease of children and adults: ultrastructural localization and variation in expression. Scand J Gastroenterol 2004; 39:1219-27.

28 Gorgun J, Portyanko A, Marakhouski Y et al. Tissue transglutaminase expression in celiac mucosa: an immunohistochemical study. Virchows Arch 2009; 455:363-73.

29 Biagi F, Campanella J, Laforenza U et al. Transglutaminase 2 in the enterocytes is coeliac specific and gluten dependent. Dig Liver Dis 2006; 38:652-8.

30 Verderio EA, Johnson T, Griffin M. Tissue transglutaminase in normal and abnormal wound healing: review article. Amino Acids 2004; 26:387-404.

31 Iismaa SE, Mearns BM, Lorand L et al. Transglutaminases and disease: lessons from genetically engineered mouse models and inherited disorders. Physiol Rev 2009; 89:991-1023.

32 Verderio EA, Johnson TS, Griffin M. Transglutaminases in wound healing and inflammation. Prog Exp Tumor Res 2005; 38:89-114.

$33 \mathrm{Kim}$ Y, Eom S, Kim K et al. Transglutaminase II interacts with rac1, regulates production of reactive oxygen species, expression of snail, secretion of Th2 cytokines and mediates in vitro and in vivo allergic inflammation. Mol Immunol 2010; 47:1010-22.

34 Maiuri MC, De Stefano D, Mele G et al. Nuclear factor kappa B is activated in small intestinal mucosa of celiac patients. J Mol Med (Berl) 2003; 81:373-9.

35 Vader LW, Stepniak DT, Bunnik EM et al. Characterization of cereal toxicity for celiac disease patients based on protein homology in grains. Gastroenterology 2003; 125:1105-13. 